\title{
Abordagem histórico-didática para o ensino da Teoria Eletrofraca utilizando simulações computacionais de experimentos históricos ${ }^{+*}$
}

Márcia da Costa ${ }^{1}$

Universidade Federal do Espírito Santo

Alegre - ES

Irinéa de Lourdes Batista ${ }^{1}$

Universidade Estadual de Londrina

Londrina - PR

\section{Resumo}

Este artigo apresenta uma proposta didática para o Ensino Superior, voltada para a discussão de temas de Física Moderna Contemporânea, que inclui a abordagem da Teoria Eletrofraca por meio de uma composição histórica dessa teoria e simulações computacionais dos experimentos históricos que contribuíram no processo de unificação das interações eletromagnéticas e fracas. Esta proposta foi elaborada com base teórica e metodológica nos princípios de abordagens histórico-didáticas, da teoria de Aprendizagem Significativa, Didática das Ciências e Unidades Didáticas. A análise de questionários e de diagramas de Gowin, utilizados para avaliar a efetividade de ensino da proposta didática, evidencia indícios positivos na aprendizagem dos alunos em relação aos conteúdos científicos e em relação à Natureza da Ciência.

Palavras-chave: Abordagem Didática; Ensino de Física; Teoria Eletrofraca; Simulação Computacional de Experimentos Históricos.

\begin{abstract}
This research presents a didactic proposal for Higher Education, focused on the discussion of Modern and Contemporary Physics, which
\end{abstract}

\footnotetext{
${ }^{+}$Historical-didactic approach for the teaching of the Electroweak Theory using computational simulations of historical experiments

* Recebido: abril de 2019. Aceito: novembro de 2019.

${ }^{1}$ E-mails: marciarscosta@hotmail.com; irinea2009@gmail.com
} 
includes the approach of the Electroweak Theory through a historical composition of this theory and computational simulations of the historical experiments that contributed in the process of unification of the electromagnetic and weak interactions. This proposal was elaborated with theoretical and methodological bases from the principles of historical didactics approaches, the theory of Meaningful Learning, Didactics of Sciences and Didactical Units. The analysis of questionnaires and Gowin's diagrams, used to evaluate the effectiveness the didactic proposal, presents positive evidences on students' learning with regard to scientific content and in relation to the Nature of Science.

Keywords: Didactic Approach; Teaching Physics; Electroweak Theory; Computational Simulation of Historical Experiments.

\section{Introdução}

Em relação ao Ensino de Física, é consenso científico a necessidade da atualização curricular da Educação Básica e da diversificação das abordagens e metodologias de ensino, uma vez que as abordagens tradicionais, na sua maioria, não conseguem despertar o interesse dos alunos e apresentam dificuldades em gerar aprendizagens significativas dos conteúdos científicos. Dentre as possíveis alternativas para melhorar o Ensino de Física, seja em nível médio ou superior, estão as abordagens que envolvem História e Filosofia da Ciência (HFC), Tecnologias de Informação e Comunicação (TIC), temas de Física Moderna Contemporânea (FMC), estudantes como protagonistas do processo de aprendizagem e que leve em consideração as particularidades da própria Física, como ciência e disciplina.

Nesse contexto, é necessário pensar na formação dos professores e futuros professores para que possam trabalhar com abordagens diversificadas em sua prática docente, uma vez que são eles que podem promover a atualização curricular e um ensino contextualizado (BATISTA, 2004) que seja significativo, articulado e integrador para estudantes. Dessa maneira, este trabalho apresenta uma proposta didática que foi investigada e elaborada metodologicamente com base em princípios da Teoria da Aprendizagem Significativa, da Historiografia e da Didática da Ciência, e considera o ensino de um tópico de FMC com uma abordagem histórico-didática que recebe o auxílio das simulações computacionais e do $\mathrm{V}$ de Gowin como facilitadores de uma aprendizagem significativa, tanto de conceitos científicos quanto de noções de Natureza da Ciência.

\section{Referenciais teórico-metodológicos da Abordagem Didática}

Toda abordagem para sala de aula deve ser planejada metodologicamente, pois de acordo com Cachapuz et al. (2001) e Adúriz-Bravo e Izquierdo (2002), ao planejar uma abor- 
dagem didática para um tema de uma disciplina, deve-se considerar as particularidades dessa disciplina, atendendo características da Didática das Ciências e centrando a atenção nos conteúdos da Ciência do ponto de vista do seu ensino e aprendizagem. Batista (2016) demonstra adicionalmente que na construção de abordagens contextualizadoras, há uma necessidade de articulação e integração de elementos oriundos dos âmbitos epistemológicos e metodológicos dos vários domínios de conhecimento científico envolvidos em uma abordagem, e que esse processo se constrói de forma dialógica como uma práxis entre os campos teórico-conceituais e a realidade escolar.

Ainda a respeito da Didática das Ciências, Cachapuz, Praia e Jorge (2004), ao tratar das orientações para o Ensino de Ciências e do que se espera que esse ensino proporcione, citam três dimensões que deveriam ser atendidas: a dimensão pós-positivista, a dimensão contextualizada e a dimensão socioconstrutivista.

A dimensão pós-positivista reflete a intenção de ensinar a Ciência e como ela se desenvolve, isto é, além de abordar os conceitos científicos, também se discute como eles foram elaborados, apresentando uma visão realista da Ciência. A dimensão contextualizada da Ciência sugere que os assuntos estudados possibilitem relações entre Ciência, tecnologia, ambiente e sociedade e a dimensão socioconstrutivista é tomada como uma das alternativas para promover um ensino mais democrático e eficiente, considerando diversas metodologias e estratégias de ensino de acordo com o contexto escolar-educacional.

Assim, a Abordagem Didática proposta neste trabalho procurou atender todas essas dimensões, uma vez que: 1) Aborda o tema da unificação eletrofraca, que contém conceitos componentes de ementas de disciplinas correlatas à Física Moderna e possibilita discussões de questões contemporâneas a respeito de teorias físicas, bem como de métodos experimentais de Física de Partículas que são utilizados até os dias atuais e avanços científicos e tecnológicos que permeiam a vida cotidiana; 2) Discute o processo de elaboração da Teoria Eletrofraca e promove reflexões a respeito da Natureza da Ciência; 3) O processo de elaboração e aplicação levou em consideração aspectos da Teoria de Aprendizagem Significativa.

Nesse sentido, defende-se que as abordagens sejam planejadas de acordo com um referencial teórico-metodológico, pois Batista (2004; 2016), Neto, Cavalcante e Ostermann (2015) e Pereira e Ostermann (2009) revelam que apesar da literatura apresentar um número significativo de produções científicas relacionadas aos conteúdos de FMC, como propostas didáticas, jogos, hipermídias, simulações computacionais, textos didáticos, entre outros, ainda são poucas as produções científicas que são fundamentadas em referenciais teóricometodológicos para a sua elaboração e que buscam investigar resultados reais em sala de aula.

Os referenciais teórico-metodológicos que guiaram a elaboração e aplicação da abordagem aqui apresentada são compostos por:

Teoria da Aprendizagem Significativa: levou-se em consideração princípios da aprendizagem significativa, como os organizadores prévios, diferenciação progressiva, reconciliação integradora e consolidação. Além do mais, foram utilizados como facilitadores da 
aprendizagem significativa as simulações computacionais e os diagramas de Gowin e dentre as condições que favorecem essa aprendizagem utilizaram-se materiais potencialmente significativos e a predisposição dos indivíduos à aprendizagem (Ausubel, 2003; Gowin; Alvarez, 2005).

Composição Histórica e Experimentos Históricos: para abordar a Teoria Eletrofraca, considerando o contexto histórico e o processo de elaboração dessa teoria, foram utilizadas duas estratégias para inserção de HFC em sala de aula: a composição histórica e os experimentos históricos. O termo composição histórica foi definido por Batista (2016), como uma construção textual (ou de outra natureza comunicativa) que reúne elementos históricos e historiográficos, epistemológicos, axiológicos e científicos para a inteligibilidade de um conteúdo científico com objetivo pedagógico e de disseminação de conhecimentos históricoepistemológicos e sociais. Já a abordagem de experimentos históricos combina a experimentação e a História e Filosofia da Ciência e podem ser utilizados de diversas maneiras. Nesta proposta eles são explorados na perspectiva das simulações computacionais e os referenciais que guiaram essa estratégia foram: Heering (2005), Chang (2011) e Metz e Stinner (2007). Ambas as estratégias foram, também, guiadas por princípios da Aprendizagem Significativa.

Unidades Didáticas: A abordagem foi composta por três Unidades Didáticas. O termo Unidade Didática é definido por Zabala (1998), como sequências de atividades estruturadas para alcançar objetivos educacionais determinados. As unidades têm a característica de manter o caráter articulador e reunir toda a complexidade da prática, ao mesmo tempo que são instrumentos que permitem incluir as três fases de uma intervenção reflexiva: o planejamento, a aplicação e a avaliação.

O planejamento de uma Unidade Didática, baseada em sequências de atividades específicas, favorece o processo formativo, pois apesar de não ser possível prever tudo o que pode acontecer, é necessário ter em mãos uma abordagem suficientemente elaborada para favorecer o processo de aprendizagem. No entanto, essa intervenção deve estar aberta a possíveis mudanças, mas não pode ser resultado de improvisação (ZABALA, 1998).

De acordo com Zabala (1998), há sequências de atividades que se adaptam melhor aos objetivos educacionais pretendidos. Assim existem diferentes sequências didáticas para o ensino, que podem compor uma Unidade Didática. O autor propõe como exemplo quatro Unidades Didáticas que se diferenciam uma da outra pelo grau de participação dos envolvidos e as características dos diferentes tipos de conteúdo.

Para alcançar os objetivos pretendidos com a abordagem didática, foi utilizado o exemplar da unidade 4, uma vez que ela permite a participação ativa dos envolvidos durante a abordagem e propicia uma variedade de atividades.

A sequência dessa unidade é composta pelas seguintes fases: 1) Apresentação de uma situação problemática relacionada com o tema; 2) Proposição de problemas ou questões; 3) Explicitação de respostas intuitivas ou suposições; 4) Proposta das fontes de informação; 5) 
Busca da Informação; 6) Elaboração das conclusões; 7) Generalização das conclusões e síntese; 8) Exercícios de memorização; 9) Prova ou exame; 10) Avaliação.

As Unidades Didáticas foram desenvolvidas com as devidas adequações, uma vez que o autor sugere que essas sequências não são rígidas e podem ser adaptadas conforme os propósitos educacionais a serem obtidos. Assim, não estão presentes os itens 8,9 e 10 devido ao fato que as atividades foram compostas por avaliações processuais, que serão descritas em seguida.

\section{Estrutura da Abordagem Didática}

Optou-se por apresentar a estrutura dessa abordagem no formato de três unidades para que os professores, se desejarem, poderem utilizá-las separadamente com as devidas adaptações. No quadro 01 são apresentadas as atividades e em seguida essas atividades são descritas com mais detalhes.

Quadro 01 - Estrutura da Abordagem Didática.

\begin{tabular}{|c|c|c|}
\hline ATIVIDADES & DURAÇÃO & \\
\hline Apresentação & 03 minutos & \multirow{6}{*}{$\begin{array}{l}\text { Atividades relaci- } \\
\text { onadas à Teoria de } \\
\text { Aprendizagem } \\
\text { Significativa }\end{array}$} \\
\hline Obtenção de conhecimentos prévios & 40 minutos & \\
\hline $\begin{array}{l}\text { Organizador Prévio: leitura do texto "Teoria Eletro- } \\
\text { fraca" }\end{array}$ & 30 minutos & \\
\hline Discussão do texto e retomada de pontos relevantes & 12 minutos & \\
\hline Introdução ao V de Gowin & 15 minutos & \\
\hline Atividades com o Diagrama de Gowin & 40 minutos & \\
\hline Como tudo começou? & 40 minutos & \multirow[t]{4}{*}{ UD1 } \\
\hline Momento de consolidação 1. & 05 minutos & \\
\hline $\begin{array}{l}\text { Atividades com o Simulador "Violação da Paridade } \\
\text { Espacial" }\end{array}$ & 40 minutos & \\
\hline Momento de consolidação 2. & 10 minutos & \\
\hline Continuando a história (1) & 50 minutos & \multirow[t]{6}{*}{ UD2 } \\
\hline Momento de consolidação 3. & 05 minutos & \\
\hline Continuando a história (2) & 30 minutos & \\
\hline $\begin{array}{l}\text { Atividades com o Simulador "Detecção das Corren- } \\
\text { tes Neutras" }\end{array}$ & 40 minutos & \\
\hline Vídeo: Gargamelle & 05 minutos & \\
\hline Momento de consolidação 4. & 10 minutos & \\
\hline Continuando a história (3) & 25 minutos & \multirow[t]{4}{*}{ UD3 } \\
\hline Vídeo: Processo de aceleração das partículas & 05 minutos & \\
\hline $\begin{array}{l}\text { Atividades com o Simulador "Detecção Indireta dos } \\
\text { Bósons } W+, W-e Z^{\circ} \text { " }\end{array}$ & 40 minutos & \\
\hline Atividades extraclasse & 04 horas & \\
\hline
\end{tabular}




\begin{tabular}{|l|l|l|}
\hline Consolidação da Teoria Eletrofraca & 10 minutos & \\
\cline { 1 - 2 } Momento de feedbacks & 10 minutos & \\
\cline { 1 - 2 } V de Gowin a respeito da Teoria Eletrofraca & 50 minutos & \\
\hline Unificação de teorias & 15 minutos & \multirow{2}{*}{$\begin{array}{c}\text { Atividades de } \\
\text { Consolidação }\end{array}$} \\
\cline { 1 - 2 } Animação do Atlas & 08 minutos & \\
\cline { 1 - 2 } Atividade com o Hypatia & 30 minutos & \\
\hline Consolidação final & 15 minutos \\
\cline { 1 - 2 } Questionários finais & 50 minutos & \\
\hline Encerramento & 05 minutos & \\
\hline
\end{tabular}

Fonte: Costa (2019).

Em termos do exemplar 4 das unidades propostas por Zabala (1998), a abordagem, descrita no quadro 01 , pode ser interpretada como um conjunto de três unidades, pois foram discutidos três experimentos e para cada um deles havia uma sequência de atividades que se encaixam em passos propostos por Zabala (1998). A seguir, no detalhamento das atividades serão exemplificados os passos da unidade 4 presentes na abordagem.

As primeiras atividades que englobam a apresentação, obtenção dos conhecimentos prévios, organizador prévio, discussão do texto e retomada de pontos relevantes, introdução ao V de Gowin e atividades com o diagrama de Gowin são atividades embasadas na Teoria de Aprendizagem Significativa, que apresentam o tema da oficina para os alunos, em termos de aspectos gerais, e introduzem o $\mathrm{V}$ de Gowin como um instrumento para o estudo de textos e experimentos. Em seguida são detalhadas essas atividades.

Apresentação: Momento em que ocorre a apresentação entre professores e alunos, caso seja necessário, aborda-se os objetivos da aula e eventuais acordos.

Obtenção dos conhecimentos prévios: De acordo com a Teoria de Aprendizagem Significativa, os conhecimentos prévios são fatores que influenciam o processo de aprendizagem. Dessa forma, nesse momento, por meio de um questionário prévio, obtêm-se os conhecimentos prévios dos alunos em relação às noções de Natureza da Ciência e aos conteúdos científicos a serem abordados durante a oficina. Esse questionário ${ }^{2}$ também pode servir como um propositor de questionamentos em relação aos assuntos a serem discutidos, com a finalidade de instigar a curiosidade dos alunos e motivá-los a participar ativamente das discussões e das atividades propostas para encontrarem as respostas para suas dúvidas.

Organizador Prévio: leitura do texto "Teoria Eletrofraca": Foi elaborado um texto ${ }^{3}$ para ser utilizado como organizador prévio para o conteúdo a ser discutido. Trata-se de um texto em um nível mais elevado de abstração, generalidade e inclusão, que se inicia com ideias conhecidas pelos alunos, como as interações fundamentais e a unificação de teorias já dis-

\footnotetext{
2 Disponível em Costa (2019).

${ }^{3}$ Este texto e os demais materiais utilizados nesta abordagem estarão disponíveis em uma página online anexada ao site do grupo de pesquisa IFHIECEM (http://www.uel.br/grupo-pesquisa/ifhiecem/index.html). Para mais informações entrar em contato com a pesquisadora pelo e-mail: marciarscosta@hotmail.com.
} 
cutidas em disciplinas do curso de formação, para então discutir o assunto de interesse, que é a unificação das interações fracas e eletromagnéticas. Assim, de acordo com Ausubel (1980; 2003), esse texto pode ser uma ponte cognitiva entre o que aluno já sabe e o que ele deveria saber, para que o novo material, a ser apresentado, possa ser aprendido de forma significativa. Os alunos podem ler o texto com calma, cada um em seu ritmo.

Discussão do texto e retomada de pontos relevantes: Após a leitura, recomenda-se retomar os pontos relevantes do texto que podem representar os subsunçores dos alunos ou se relacionar com os mesmos. Assim, promove-se um momento de consolidação na tentativa de possibilitar que os alunos tenham entendido ou recordado os conceitos que serão necessários para a compreensão dos conteúdos que serão introduzidos.

Introdução ao V de Gowin: Como o V de Gowin foi escolhido como um dos facilitadores de aprendizagem, há a necessidade que ele seja apresentado aos alunos, pois, de acordo com a literatura, ele é pouco utilizado e possivelmente os alunos nunca trabalharam com esse instrumento.

Atividades com o Diagrama de Gowin: Atividades práticas com o V de Gowin precisam ser desenvolvidas para que os estudantes se familiarizem com essa metodologia de ensino e aprendizagem que pode ser utilizada em diversos momentos do estudo de uma temática. Nesse momento específico, sugere-se que sejam abordados exemplos com assuntos conhecidos pelos estudantes. No caso dessa oficina propõe-se um exemplo com a Lei de Ohm, voltado para um experimento que pretende medir a resistência de um resistor $\mathrm{X}$ e analisar se o resistor é ôhmico. Em seguida, é necessário que os estudantes pratiquem para tirar suas dúvidas. Isso pode ser feito com o texto "Teoria Eletrofraca", pois o V de Gowin também pode ser utilizado para estudar textos (GOWIN; ALVAREZ, 2005; MOREIRA, 2006; VALADARES, 2014).

Como tudo começou? Essa etapa, que se segue após a introdução do tema com o organizador prévio, tem a função de promover uma diferenciação progressiva dos conceitos abordados, de forma geral, no texto "Teoria Eletrofraca" e também discutir noções da Natureza da Ciência. Essas atividades têm o objetivo de situar o aluno no contexto no qual se deu início aos questionamentos a respeito da conservação da paridade nas interações fracas e promover um entendimento do processo de elaboração científica que levou ao desenvolvimento do experimento que possibilitou a obtenção de respostas em relação ao comportamento da paridade nas interações fracas.

Nessa etapa da oficina começa a primeira unidade, de acordo com Zabala (1998). As atividades dessa etapa são compostas por exposição do tema e dos problemas que levaram ao experimento que possibilitou respostas em relação ao comportamento da paridade no decaimento beta. Nessa fase estariam presentes os passos 1, 2 e 3 do exemplar da unidade 4.

Essa etapa é composta por exposições do tema, elaboradas durante a pesquisa por meio de slides e momentos de discussão a respeito de questões propostas pela pesquisadora implementadora da abordagem, ou por estudantes participantes na implementação. Essas 
questões trataram tanto do conteúdo científico, quanto de noções de Natureza da Ciência. Dentre as noções abordadas, está a participação feminina na Ciência, o trabalho colaborativo e o caráter provisório do conhecimento científico.

Momento de consolidação 1: nesse instante propõe-se a retomada de alguns conceitos e situações relevantes para que os estudantes entendam a problematização para a realização do experimento que irão simular computacionalmente, bem como as possíveis implicações dos resultados obtidos pelo experimento. Dessa forma, os estudantes podem ser questionados a respeito das seguintes questões: as teorias vigentes, da época que estão estudando, conseguem explicar o problema $\theta-\tau$ ? O que se sabe a respeito do comportamento da paridade nas interações fundamentais? Quais as possíveis implicações em relação ao resultado do experimento?

Dessa forma, ao final dessa etapa os alunos foram apresentados ao tema em discussão, que é o comportamento da paridade nas interações fracas e ao mesmo tempo possuem um problema para resolver: a conservação ocorre ou não?

Em seguida são desenvolvidos os passos 4, 5 e 6 do exemplar da unidade 4, nos quais são propostas as fontes de informações, é feita a busca de informações e são elaboradas as conclusões a respeito do problema a ser resolvido.

Atividades com o Simulador "Comportamento da Paridade nas Interações Fracas": Nesse momento os alunos irão receber um texto (fonte de informação), elaborado nesta pesquisa, para auxiliar na exploração da simulação computacional ${ }^{5}$ (busca da informação) e como resultado da atividade deverão elaborar um V de Gowin (elaboração das conclusões), para que eles possam registrar seu entendimento do processo de experimentação que estavam testando.

O texto que eles recebem a respeito do experimento deve conter informações teóricas que os ajudem a entender o contexto prévio ao experimento, em termos de teorias, princípios e conceitos, bem como, dicas para orientar a montagem do experimento na simulação computacional. Assim, o público alvo pode cruzar as informações contidas no texto com os elementos textuais da simulação e resolver os desafios impostos pela simulação. De outra forma, o texto também auxilia na elaboração do $\mathrm{V}$ de Gowin, uma vez que sua leitura é feita no tempo individual necessário para o entendimento das informações teórico-conceituais.

Nessas etapas do processo a pesquisadora implementadora assume o papel de orientadora, apenas fornecendo uma breve explicação a respeito das simulações e auxiliando os alunos a resolverem suas dúvidas, de maneira que eles assumam uma posição completamente ativa em relação às atividades.

Ao final de cada simulação computacional, o próprio software direciona os alunos para a continuação do conteúdo, com reflexões a respeito das implicações dos resultados de cada um dos experimentos simulados computacionalmente.

\footnotetext{
4 Vide nota de rodapé de número 2.

${ }^{5}$ Vide nota de rodapé de número 2.
} 
Foram elaboradas três simulações dos experimentos, em sequência histórica, que colaboraram para o processo de unificação das interações eletromagnéticas e fracas e a simulação computacional utilizada nesta etapa que descrevemos é aquela a respeito do experimento que levantou questionamentos a respeito da propriedade de paridade da interação fraca e cujos desdobramentos resultaram na formulação da Teoria Eletrofraca.

A interface dessa simulação é voltada para a realização desse primeiro experimento, na qual os alunos montam e testam o experimento até chegarem as conclusões a respeito do questionamento que levou a exploração dessa simulação. A Fig. 01 exemplifica uma tela da interface dessa simulação.

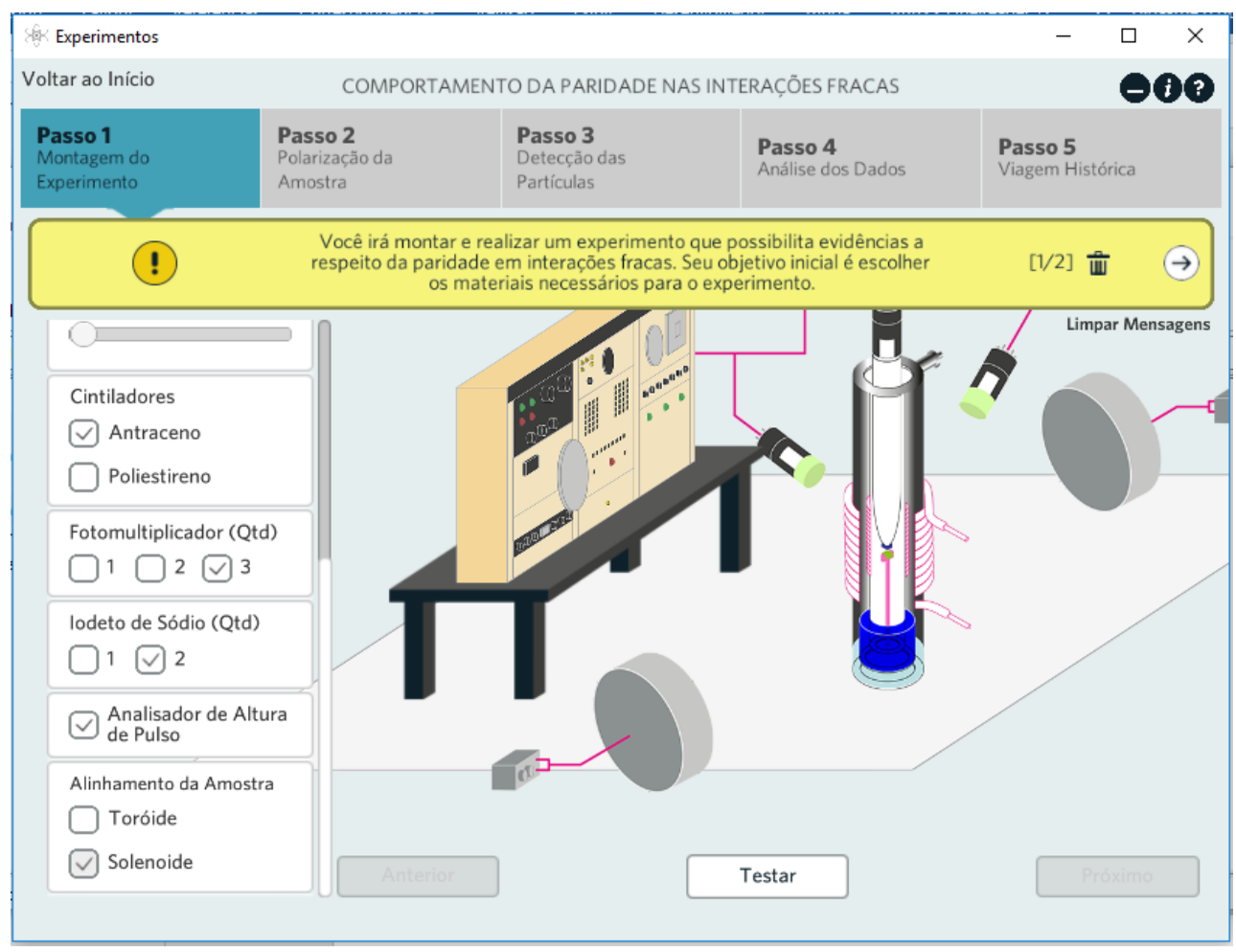

Fig. 01 - Tela da interface da simulação do experimento que estudou o comportamento da paridade nas interações fracas. Fonte: as autoras.

É possível perceber nessa figura que a simulação desse experimento foi composta por cinco etapas. Na primeira, pode-se montar e testar o experimento, testar as alternativas com base no texto e nas dicas da simulação para montar o experimento corretamente ${ }^{6}$. Após a montagem, executa-se o experimento polarizando a amostra, detectando as partículas e analisando os resultados. Por fim, na última etapa da simulação, pode-se visualizar fotos históricas do experimento original e obter um direcionamento para as próximas discussões e atividades, pois ao responder uma pergunta outras surgem e assim o conhecimento científico vai se de-

\footnotetext{
6 Aqui "corretamente" se refere a um modelo, que neste caso é o experimento histórico realizado pela cientista Chien-Shiung Wu e sua equipe em 1957.
} 
senvolvendo. Esse processo é guiado por mensagens que orientam e advertem durante a exploração da simulação.

Momento de consolidação 2: Nesse passo, se discute o resultado do experimento com estudantes e abordam-se as possíveis implicações, pois caso não as tenham identificado no V de Gowin, esse é o momento para oportunizar essa discussão. Dentre as noções de Natureza da Ciência $(\mathrm{NdC})$ que podem ser discutidas nesse momento está a questão da provisoriedade do conhecimento científico, uma vez que o resultado do experimento que simularam e de outros que foram realizados posteriormente, naquela época, mudaram a ideia que se tinha a respeito do comportamento da paridade nas interações fracas.

Essas atividades compõem o passo 7 do exemplar da unidade 4, na qual se discute as conclusões obtidas na solução do problema e com base nas sínteses dos resultados é possível inferir o que pode acontecer com o conjunto de conhecimentos discutidos na solução do problema.

Em seguida, começa outra unidade que vai seguir os mesmos passos da unidade anterior, mas para abordar agora o desenvolvimento do conhecimento científico que levou a realização do experimento que evidenciou a presença de correntes neutras. Essa unidade apresenta os passos 1, 2 e 3 mais extensos que os correspondentes nas outras duas unidades, pois tratase do processo de desenvolvimento teórico-matemático da Teoria Eletrofraca. Assim, esses passos são representados por: Continuando a história (1), Momento de consolidação 3 e Continuando a história (2).

Continuando a história (1): Como o objetivo da oficina era elucidar o processo de desenvolvimento da Teoria Eletrofraca, entre as atividades, dá-se continuação à explicação do processo histórico desse desenvolvimento. Nessa etapa a pesquisadora implementadora aborda a reformulação da Teoria de Fermi para a forma V - A, a Teoria de Gauge, a estrutura dos grupos de simetria, as primeiras ideias a respeito dos bósons mediadores, a participação do físico brasileiro José Leite Lopes, as correntes neutras, Teoria de Gauge não Abeliana, as tentativas de Glashow, Salam e Weinberg e o mecanismo de Higgs.

Esses assuntos foram abordados em exposições de partes do processo que se sucedeu após a evidência experimental da Violação da Paridade nas interações fracas, a proposição da Teoria Eletrofraca, até a detecção das correntes neutras. Foram feitas exposições por meio de slides $^{7}$, discussões, leitura de um trecho de uma palestra ${ }^{8}$ proferida pelo cientista brasileiro Leite Lopes, "Sobre os bósons pesados e a existência do bóson neutro", a atividade "Tricky Tracks", proposta por Lederman e Abd-El-Khalick (1998) e um vídeo que explica o Mecanismo de Higgs.

\footnotetext{
7 Vide nota de rodapé de número 2.

8 José Leite Lopes: in ALVES, G. CARUSO, F. MOTTA, H. SANTORO, A (Ed.). O mundo das partículas de hoje e de ontem. Rio de Janeiro, CBPF, 2000, p. 59-65.
} 
Essas atividades tiveram o objetivo de explicar o conteúdo científico e discutir noções de Natureza da Ciência, como: o caráter "humano" dos cientistas, diferença entre observações e inferências, o formalismo matemático na construção do conhecimento científico.

Momento de consolidação 3: Após a introdução de todos esses assuntos novos, antes de dar continuidade à história do desenvolvimento da Teoria Eletrofraca, convém retomar recursivamente pontos relevantes para que os alunos compreendam como se chegou na proposição da Teoria Eletrofraca e das correntes neutras.

Continuação da história (2): Nessa etapa são expostas algumas das soluções encontradas para os problemas que impediam a formulação completa da Teoria Eletrofraca, entre elas: o motivo pelo qual as correntes neutras não eram observadas no decaimento de partículas estranhas e a renormalização da teoria. Nesse caso, é dada ênfase para a relevância do formalismo matemático para o desenvolvimento de teorias científicas e são fornecidos detalhes a respeito da busca experimental pelas correntes neutras.

Ao final dessas três etapas, os conteúdos científicos envolvidos na elaboração da Teoria Eletrofraca foram apresentados e há como novo objetivo investigativo-pedagógico a solução de outro problema: as correntes neutras existem?

$\mathrm{Na}$ sequência são seguidos os passos 4, 5 e 6 do exemplar da unidade 4, nos quais são fornecidas as fontes de informação para solução do problema, são realizadas as atividades de busca de resposta para o problema e elaboradas as conclusões com base nas respostas obtidas. Esses passos são cumpridos na etapa das Atividades com o Simulador "Detecção das Correntes Neutras.

Atividades com o Simulador "Detecção das Correntes Neutras": Assim como no caso da atividade com o simulador do encontro anterior, os alunos recebem um texto (fonte de informação), elaborado para essa pesquisa, para auxiliar na exploração da simulação computacional (busca da informação) e na elaboração do V de Gowin (elaboração das conclusões). Na Fig. 02 é apresentada uma tela da interface da simulação computacional do segundo experimento.

Essa tela mostra que a simulação deste experimento segue etapas parecidas com a do experimento anterior. Nela, pode-se testar várias montagens do experimento e após a montagem correta que se torna possível prosseguir para as demais etapas, tendo como guia as mensagens que orientam nas atividades e além de advertir de algum erro, também explica o motivo do erro, apresentando a oportunidade de se aprender com eventuais erros. Aqui uma etapa nova é a de dados históricos, na qual é apresentada a fotografia do evento original no qual estava evidente a presença das correntes neutras e informações a respeito dessa detecção.

Após essas etapas, é realizado o passo 7 do exemplar da unidade 4. Nessa etapa é utilizado um vídeo que descreve registros históricos do experimento e em seguida é realizada uma síntese dos resultados para tentar inferir quais são os próximos passos no decorrer do estabelecimento da Teoria Eletrofraca. 


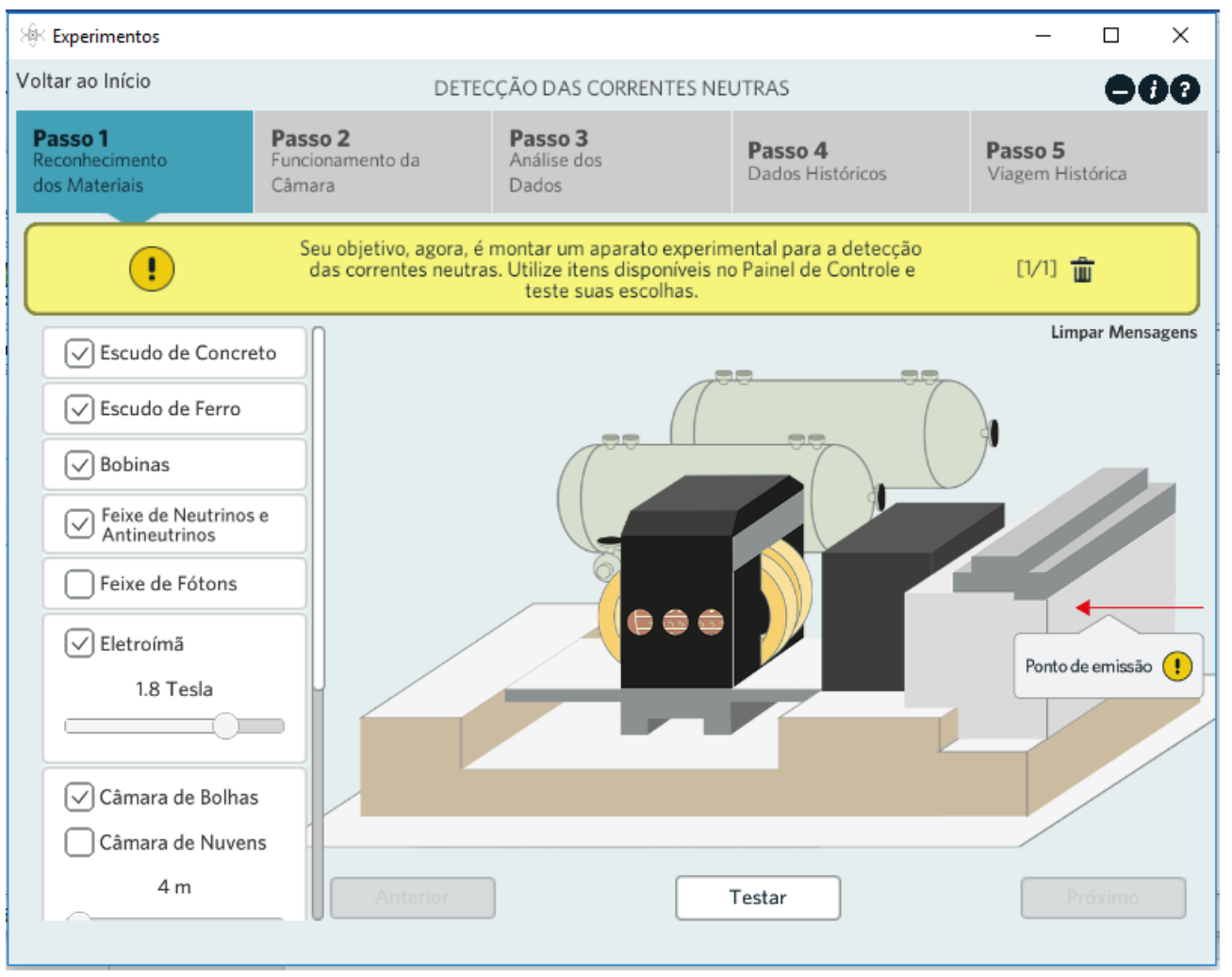

Fig. 02 - Tela da interface do experimento a respeito das correntes neutras. Fonte: as autoras.

Video - Gargamelle: Após as atividades envolvendo a simulação do experimento com a Câmara de Gargamelle, é exibido um vídeo ${ }^{9}$ que explica o processo de construção e execução do experimento, com a finalidade de apresentar os registros históricos.

Momento de consolidação 4: Nessa etapa a pesquisadora implementadora aborda o resultado do experimento e implicações deste na trajetória de partículas para a detecção dos bósons mediadores da interação fraca.

Esta etapa dá início à terceira unidade, a qual vai apresentar os esforços e desafios enfrentados para a realização do experimento que detectou indiretamente os bósons $\mathrm{W}+, \mathrm{W}$ - e $Z^{0}$. Nela são apresentados os passos 1, 2 e 3 do exemplar da unidade 4 na etapa Continuação da história (3), ao final da qual são apresentados os desafios para a realização do experimento e tem-se como tarefa a realização virtual desse experimento para responder se esses bósons existem, ou não.

Continuação da história (3): Nessa etapa a pesquisadora implementadora aborda os aprimoramentos tecnológicos e as parcerias para o desenvolvimento de um experimento que fosse capaz dessa deteç̧ão dos bósons mediadores da interação fraca, os desafios enfrentados, como detectar esses bósons, o detector UA1, e o processo de aceleração das partículas até a

\footnotetext{
${ }^{9}$ Cern-Movie-1971-001 (Editado).
} 
colisão no detector. Esses assuntos foram tratados com auxílio de slides e um vídeo que explica o processo de aceleração das partículas. Dentre as noções de $\mathrm{NdC}$ a serem discutidas estão: atribuições de um cientista e trabalho colaborativo.

Em seguida, realizam-se os passos 4, 5 e 6 do exemplar da unidade 4, nos quais obtém-se fontes de informação, buscam-se as informações e elaboram-se as conclusões a respeito do problema a ser resolvido.

Convém ressaltar que houve mais um experimento relevante no processo de unificação dessas interações, o experimento que detectou a violação da paridade em átomos. No entanto, por falta de informações histórico-técnicas detalhadas a respeito desse experimento, ele não foi simulado computacionalmente, e sim foi abordado teoricamente.

Atividades com o simulador "Detecção Indireta dos Bósons $W+, W$ - e $Z^{0}$ ”: um texto é fornecido (fonte de informação) para auxiliar na exploração da simulação computacional (busca de informação) e elaboração do $\mathrm{V}$ de Gowin (elaboração das conclusões) referente ao experimento simulado. Na Fig. 03 é apresentada uma tela dessa simulação.

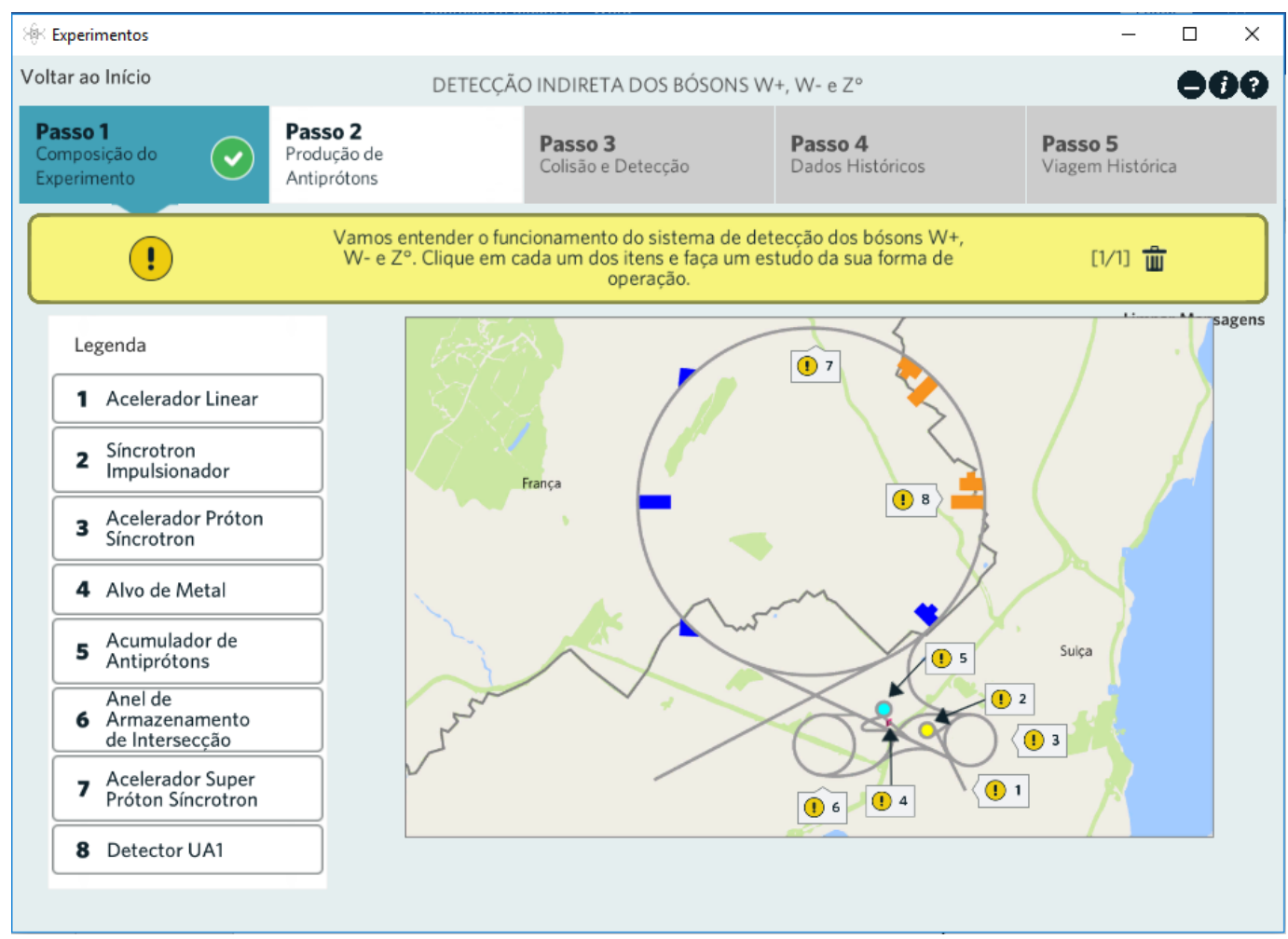

Fig. 03 - Tela da interface do experimento da detecção indireta dos bósons da interação fraca. Fonte: as autoras.

Nessa simulação, diferente das duas primeiras, a primeira etapa é mais informativa do que interativa. Nesse primeiro passo, obtém-se conhecimento do funcionamento do siste-

\footnotetext{
10 CERN CONTROL CENTRE \"From the LINAC to the LHCl" - CERN-VIDEORUSH-2014-043-001 (Editado).
} 
ma de aceleração e detecção dos bósons para na segunda etapa ser possível interagir com a simulação no processo que vai desde o início da aceleração dos prótons, a produção e aceleração de antiprótons, a colisão e detecção das partículas geradas nas colisões. Essa simulação também apresentou as fotografias dos eventos originais que evidenciaram as detecções dos bósons da interação fraca e uma viagem histórica com as fotografias originais de algumas etapas da montagem do detector UA1.

Em seguida, há uma atividade de síntese dos resultados de todas as unidades para entender o processo de elaboração da Teoria Eletrofraca com base nos desenvolvimentos teóricos e experimentais realizados e discutidos anteriormente. Para isso foi elaborado um texto parecido com o organizador prévio, porém com mais detalhamento dos processos.

Sugere-se que na leitura desse texto, em atividade extraclasse, reflita-se a respeito do processo de elaboração da Teoria Eletrofraca e se pense na estrutura de um V de Gowin que represente esse processo.

Atividades extraclasse: Como são vários os conteúdos abordados na oficina e somente as atividades em sala de aula podem não ser suficientes para uma aprendizagem de familiarização com o processo de desenvolvimento da teoria estudada, sugere-se que se tenha um material para ser revisto com calma. Para isso, foi elaborado um texto específico, com base no texto "Teoria Eletrofraca" (utilizado como organizador prévio). Esse novo texto contém a diferenciação progressiva dos conceitos apresentados no texto do primeiro encontro ("Teoria Eletrofraca”). Como atividade proposta para leitura e interpretação desse texto, sugere-se a construção de um V de Gowin que represente todo o processo de elaboração da Teoria Eletrofraca.

Após a atividade extraclasse, espera-se o alcance de uma compreensão com mais detalhes do processo e que ocorram dúvidas ou curiosidades a respeito do assunto, o que pode ser discutido na etapa de Consolidação da Teoria Eletrofraca, na qual são retomados os fatores que influenciaram na elaboração dessa teoria.

Consolidação da Teoria Eletrofraca: Nessa etapa, aproveita-se para abordar os resultados do experimento simulado e suas implicações, bem como promover uma revisão geral de todos os fatores que contribuíram no processo de desenvolvimento dessa teoria.

Antes da elaboração do $\mathrm{V}$ de Gowin relacionado ao texto da atividade extraclasse e que representa o processo de elaboração da Teoria Eletrofraca, convém realizar uma atividade de feedbacks, na qual, ao analisar os diagramas $\mathrm{V}$ das atividades anteriores e as respostas dadas em relação à $\mathrm{NdC}$, pode-se explicitar possíveis equívocos de estrutura ou conceituais.

Momento de feedbacks: No decorrer da implementação dessa abordagem é possível perceber se possíveis equívocos ocorrem no público alvo em relação às noções de $\mathrm{NdC}$ e nas elaborações do V de Gowin. Assim, nesse momento é possível discutir os pontos que eventualmente não ficaram claros para eles, o que pode levá-los a corrigir esses equívocos em atividades posteriores ou reificar positivamente a estrutura cognitiva.

${ }^{11}$ Vide nota de rodapé de número 2. 
$V$ de Gowin a respeito da Teoria Eletrofraca: Essa atividade tem o objetivo de promover um entendimento do processo de elaboração da Teoria Eletrofraca, bem como servir de instrumento de avaliação de como se dá o entendimento desse processo de unificação das teorias eletromagnéticas e fracas. Essa atividade pode ser mediada pelo texto fornecido para as atividades extraclasse.

Ao final dessa etapa termina-se a terceira unidade e com isso é possível explicitar a dinâmica da construção do conhecimento científico articulado à dinâmica da elaboração do conhecimento de aprendizes, como um processo de conhecimento científico no qual uma questão científica leva a outra, que leva a outra e assim por diante. Na dinâmica de facilitação da elaboração do conhecimento por aprendizes, uma Unidade Didática leva a outra e assim por diante.

Por fim, são discutidas as generalizações do tema, a questão da unificação das teorias, da detecção de partículas em aceleradores, uma ideia de como são feitas as pesquisas nessa área da Física e a consolidação final, na qual se retomam conhecimentos científicos e noções de $\mathrm{NdC}$ por meio de questionamentos para permitir que aprendizes expressem o que entenderam do assunto.

Unificação de Teorias: Nessa etapa da oficina se discute o conceito de unificação e sua relação no desenvolvimento científico.

Animação Atlas: Sugere-se uma atividade para explicar o funcionamento de sistemas de detecção de partículas, para isso é utilizada uma animação disponibilizada pelo experimento Atlas ${ }^{12}$ que planifica detectores e mostra uma animação das trajetórias de diferentes partículas nos detectores. Na figura a seguir é apresentada a interface dessa animação.

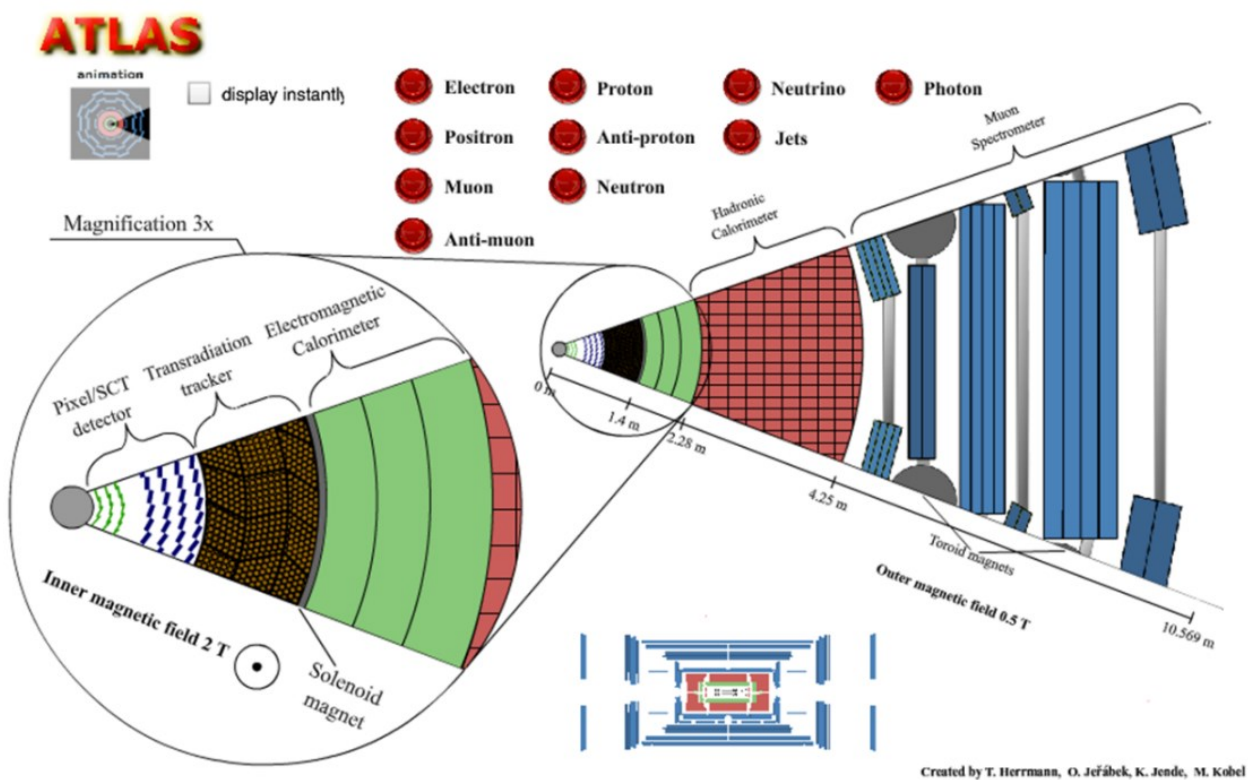

Fig. 04 - Interface da animação Atlas.

Fonte: http://atlas.physicsmasterclasses.org/pt/zpath_playwithatlas.htm.

12 Disponível em: <http://atlas.physicsmasterclasses.org/pt/zpath_playwithatlas.htm>. 
Atividade com Hypatia: Hypatia ${ }^{13}$ é um software desenvolvido pelo experimento ATLAS para o ensino de Física de Partículas. Por meio dele é possível analisar dados reais do CERN e fornecer aos estudantes um exemplo de como são desenvolvidas as pesquisas experimentais nessa área. Nessa etapa da oficina a pesquisadora implementadora apresenta o software citado e sugere que aprendizes realizem uma atividade de identificação de possíveis decaimentos do bóson $Z^{0}$. Na Fig. 05 é apresentada a interface desse software.

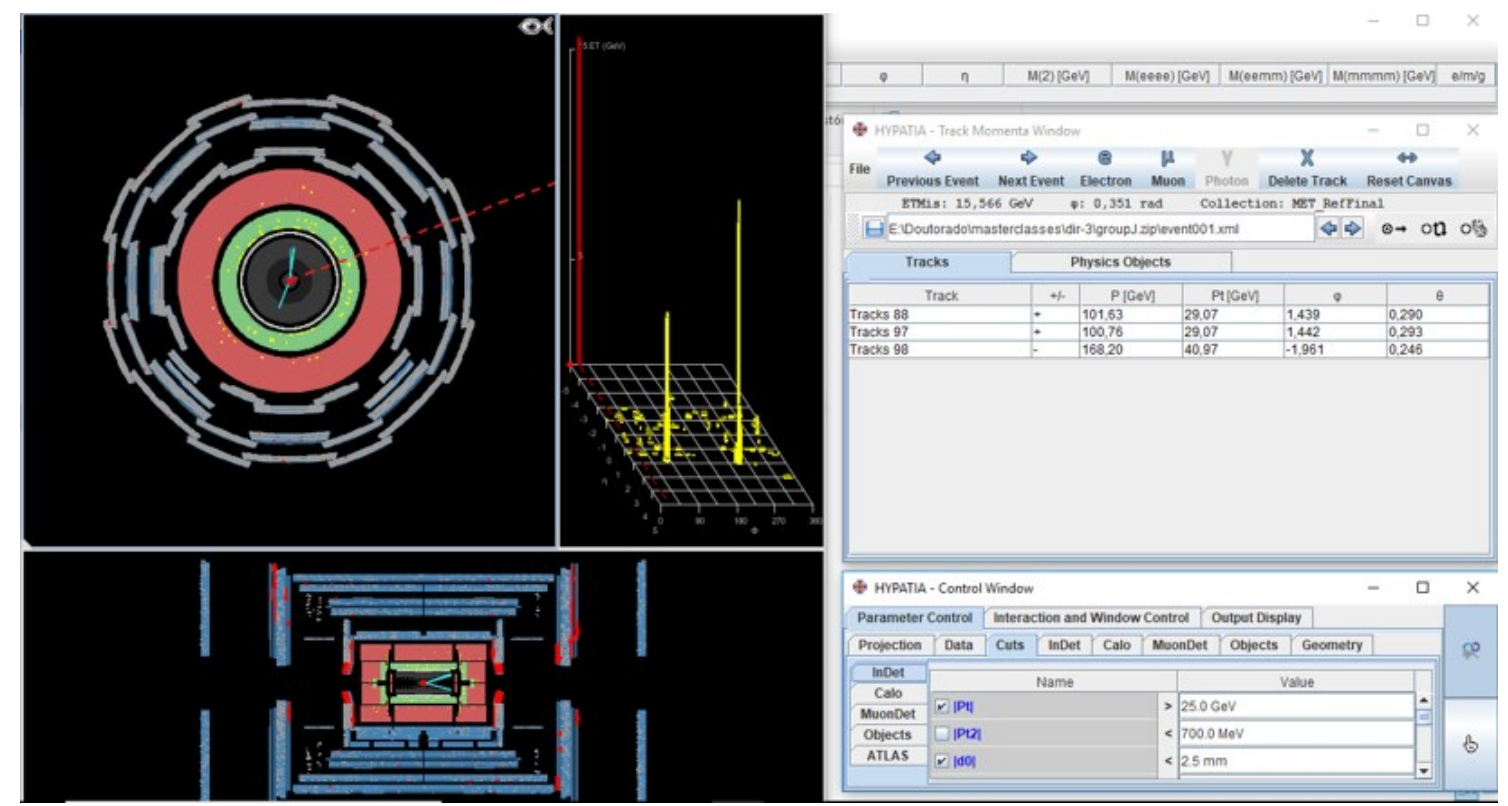

Fig. 05 - Interface do software Hypatia. Fonte: Software Hypatia.

Consolidação final: como atividade para encerrar a discussão dos conteúdos promove-se uma discussão a respeito dos conteúdos científicos e noções de $\mathrm{NdC}$ que foram abordadas no decorrer da oficina. Essa consolidação pode ser realizada por meio de questionamentos, na qual se sugere que participantes da oficina expressem o que entenderam a respeito das questões e possam discutir com colegas participantes suas respostas.

Questionários finais: Para finalizar as atividades são distribuídos dois questionários, o questionário posterior, que é composto pelas mesmas questões do questionário prévio, e um questionário de avaliação da abordagem para que aprendizes opinem a respeito da metodologia de ensino e dos recursos didáticos utilizados.

Convém ressaltar que caso docentes desejem utilizar somente uma das Unidades Didáticas, é necessário realizar adaptações ao início e ao final da abordagem para que fiquem condizentes com o que se deseja abordar.

13 Nesse link é possível fazer download do software e encontrar informações de como manuseá-lo: $<$ http://atlas.physicsmasterclasses.org/pt/zpath_data.htm>. 
Em relação ao tempo didático, esse foi o tempo sugerido para as atividades, mas isso não é uma regra. Pode ser que algumas atividades demandem mais ou menos tempo de acordo com o nível de aprendizado prévio do público alvo.

\section{Resultados de uma aplicação em sala de aula}

Essa abordagem foi aplicada com alunos do curso de Licenciatura em Física da Universidade Estadual de Londrina, no formato de uma Oficina de Pesquisa, com três encontros presenciais de $4 \mathrm{~h}$ e $4 \mathrm{~h}$ de atividades extraclasse. Participaram dessa oficina nove alunos, todos que já tinham cursado ou estavam cursando a disciplina de Física Moderna. Nessa oportunidade, foram analisados os dados que poderiam indicar indícios e aprendizagem significativa em relação aos conteúdos científicos abordados e de noções de Natureza da Ciência. Os dados oriundos de questionários e de diagramas de Gowin elaborados pelos alunos foram analisados à luz da Análise de Conteúdo de Bardin (1977; 2011).

Não é o objetivo mostrar aqui uma análise sistemática dos resultados obtidos por meio dos questionários e diagramas que será objeto de outra publicação de pesquisa. Mas, a título de exemplificação dos resultados desta abordagem didática, alguns resultados serão apresentados.

Em relação aos conteúdos científicos, os dados obtidos mostraram que a maioria dos conceitos discutidos eram novidade para o público alvo. Assim, a abordagem foi uma oportunidade de assimilação de conteúdos que podem vir a se tornar subsunçores para aprendizagens futuras. Além disso, houve estudantes que passaram a apresentar reconciliação integradora em suas elaborações ao final da abordagem, ou seja, utilizaram conceitos novos, discutidos na oficina, para explicar conceitos que eles já tinham algum conhecimento. Para exemplificar esses casos pode-se citar a resposta de estudantes para a questão que investigava o seu conhecimento a respeito das correntes neutras. No início, a maioria do público alvo não sabia do que se tratava, como é possível notar nas suas respostas: "Não conheço o termo" (A8), "Não sei" (A4), "Nem ideia" (A1). Enquanto que ao final da abordagem a maioria desse público conseguiu entender do que se tratava: "Correntes neutras são aquelas que não alteram a carga da partícula." (A8), "Bósons de interação com carga neutra que não afetam a carga dos processos. Correntes carregadas alteram a carga do processo e são formadas por bósons carregados" (A4), "São correntes de partículas que não alteram a carga, diferente das correntes carregadas que alteram a carga elétrica." (A1).

Já em relação aos indícios de reconciliação integradora, pode-se citar os casos em que estudantes descrevem as interações eletromagnéticas e fracas e o decaimento beta, uma vez que após a abordagem começam a adotar conceitos discutidos na abordagem para explicar outros, por exemplo: decaimento beta: "No decaimento beta, um quark up (down) do próton (nêutron) decai em um quark down (up), formando um nêutron (próton), e mais um bóson $W^{+}$ $(W)$, que eventualmente decai em um pósitron (elétron) e um neutrino (antineutrino) " (A3). Interação fraca: "Processo interativo mediado por $W^{+}, W$ e $Z^{0}$." (A5). Interação Eletromag- 
nética: "Envolve prótons e elétrons e é descrita por U(1) que descreve o comportamento do campo." (A8).

Nessas respostas, há o registro dos conceitos dos bósons $W^{+}, W$ e $Z^{0}$ e $U(1)$ para explicar conceitos explicado por estudantes em relação a algum conhecimento prévio. Desse modo, a abordagem contribuiu para que enriquecessem os subsunçores já existentes e promoveu um aumento de vocabulário científico e recursividade, utilizando uma linguagem condizente com os assuntos estudados.

Ao refletir a respeito da contribuição dessa Abordagem Didática para a problematização de noções de $\mathrm{NdC}$, percebe-se que os indícios de melhores resultados foram para as questões relacionadas às visões empírico-indutivistas da experimentação e do papel dos experimentos na elaboração do conhecimento científico. Já em relação a noção que os alunos apresentavam a respeito da provisoriedade do conhecimento científico, da ciência não neutra e da participação da criatividade e imaginação no desenvolvimento científico, pode-se dizer que já no início da abordagem a maioria dos participantes apresentava noções menos imprecisas a respeito desses aspectos. Isso pode ser justificado pela sua formação anterior, já que em grande parte já tinham tido contato com discussões relacionadas a História e Filosofia da Ciência em disciplina específica. Assim, para casos de estudantes que não tenham tido esse contato prévio pode ser que esta abordagem consiga um nível de sensibilização maior em relação às noções de Natureza da Ciência.

$\mathrm{O} \mathrm{V}$ de Gowin se mostrou um instrumento efetivo para o entendimento do processo de desenvolvimento da Teoria Eletrofraca e também auxiliou na compreensão dos desenvolvimentos experimentais ao longo da História da Física que contribuíram para a unificação das interações mencionadas. Por meio dos diagramas foi possível observar indícios de aprendizagem significativa na identificação de reconciliação integradora entre conceitos científicos e, em três casos de estudantes, também foi possível notar indícios de aprendizagem de noções de Natureza da Ciência. No entanto, a pesquisa identificou dificuldades no início de sua adoção como instrumento pedagógico, com a ocorrência de algumas confusões entre princípios e conceitos no público alvo. Assim, recomenda-se que as atividades que visam a familiarização de aprendizes com o $\mathrm{V}$ de Gowin sejam bem detalhadas para que o público alvo não tenha dúvidas a respeito dos elementos epistemológicos do $\mathrm{V}$ de Gowin.

Em relação à opinião de aprendizes a respeito da abordagem, suas impressões mostraram-se positivas, principalmente no que se refere as simulações computacionais dos experimentos. Dentre os pontos positivos citados estão: as simulações permitem que se aprenda mais em menos tempo; desmistificação de cientistas e da Ciência; simulações e textos originais para o ensino de Física; apresentar os experimentos históricos por meio das simulações.

Convém ressaltar que a ideia de que as simulações "permitem que se aprenda mais em menos tempo" é a opinião de um dos estudantes e não tem o objetivo de passar uma impressão ingênua de que as simulações podem adquirir o papel de "salvadoras" do processo de 
ensino e aprendizagem, mas que, desde que elaboradas e utilizadas de maneira adequada, podem proporcionar resultados como esse.

Dentre as sugestões de participantes, a metade do público alvo sugeriu que encontros de 4 horas são cansativos e que as atividades poderiam ser realizadas em encontros com uma carga horária menor em um número maior de encontros. Dessa maneira, sugere-se que abordagens futuras levem em consideração esse aspecto.

\section{Considerações}

Essa Abordagem Didática surgiu com o objetivo de proporcionar a docentes da disciplina de Física Moderna ou correlatas, bem como estudantes de licenciatura que estejam cursando ou já tenham cursado essas disciplinas e desejam aprender assuntos a respeito da Física de Partículas, em especial a respeito da Interação Eletrofraca. A proposta foi elaborada para que pudesse dar aos alunos uma ideia de práticas que envolvessem História e Filosofia da Ciência, temas de FMC e simulações computacionais voltadas para a aprendizagem de conteúdos científicos e de noções de Natureza da Ciência.

Desse modo, docentes podem contar com um material de baixo custo e diversificadas atividades para abordar o processo de desenvolvimento da Teoria Eletrofraca, ou partes dele se assim quiserem. As simulações permitem que os professores e alunos tenham contato com experimentos históricos que seriam inviáveis de uma reprodução real, seja por aspectos materiais, financeiros ou espaciais. Assim, o fato de terem sido simulados computacionalmente possibilita que possam ser utilizados em sala de aula com facilidade, dispondo apenas de computadores para estudantes, ou em últimos casos apenas com uma projeção multimídia.

Espera-se que os resultados alcançados nesta investigação possam inspirar docentes e que esta abordagem se torne uma alternativa para disseminação de conhecimento científico, contextualização no Ensino de Física, compreensão da Natureza da Ciência e promova aulas investigativas, desafiadoras e reflexivas, proporcionando o protagonismo a estudantes no processo de aprendizagem, com objetivo de alcançar uma Educação Científica contemporânea e de boa qualidade.

\section{Agradecimentos}

As autoras gostariam de agradecer a equipe Multidisciplinar composta pelo professor Dr. Jacques Duílio Brancher, pelo programador Yago Henrique Pereira e pelo designer Murilo Crivellari Camargo, que colaboraram na elaboração das simulações computacionais. Também agradecem ao grupo de pesquisa IFHIECEM pelo apoio e colaboração, bem como à Capes pela concessão de uma bolsa de doutorado pelo período de dois anos e que contribuiu para a realização deste trabalho. 


\section{Referências}

ADÚRIZ-BRAVO, A.; IZQUIERDO, Y. M. Acerca de la didáctica de las ciencias como disciplina autónoma. Revista Electrónica de Enseñanza de las Ciencias, Vigo, v. 1, n. 3, p. 130-140, 2002.

AUSUBEL, D. P. Aquisição e retenção de conhecimentos: Uma perspectiva cognitiva. Tradução: TEODORO, V. D. Lisboa: Editora Plátano, 2003. 243 p.

BARDIN, L. Análise de Conteúdo. Lisboa: Edições 70, 1977.

BARDIN, L. Análise de Conteúdo. Trad. RETO, L. A.; PINHEIRO, A. São Paulo: Edições $70,2011$.

BATISTA, I. L. Uma adoção da História e Filosofia da Ciência no desenvolvimento dos saberes docentes interdisciplinares. In: BATISTA, I. L. (Org). Conhecimentos e saberes na educação em ciências e matemática. Londrina: Editora Eduel, 2016. p. 157-167.

BATISTA, I. O ensino de teorias físicas mediante uma estrutura histórico-filosófica. Ciência \& Educação, v. 10, n. 3, p. 461-476, 2004.

CACHAPUZ, A. F. PRAIA, J.; JORGE, M. Da Educação em Ciência às orientações para o ensino de Ciências: um repensar epistemológico. Ciência \& Educação, Bauru, v. 10, n. 3, p. 363-381, dez, 2004.

CACHAPUZ, A.; PRAIA, J.; PÉREZ, G. D.; CARRASCOSA, J.; MARTÍNEZ-TERRADES, F. A emergência da didáctica das ciências como campo específico de conhecimento. Revista Portuguesa de Educação, Minho, v. 14, n. 1, p. 155-195, 2001.

CHANG, H. How historical experiments can improve scientific knowledge and science education: the cases of boiling water and electrochemistry. Science \& Education, v. 20, p. $317-$ $341,2011$.

COSTA, M. experimentos históricos em ambiente virtual: uma abordagem históricodidática a respeito da teoria eletrofraca para o estudo de física de partículas no ensino superior. 2019. 423 f. Tese (Doutorado em Ensino de Ciências e Educação Matemática) Universidade Estadual de Londrina, Londrina.

GOWIN, D. B.; ALVAREZ, M. A. The art of educanting with V diagrams. Cambridge Universit Press, 2005. 231 p. 
HEERING, P. Analysing unsuccessful experiments and instruments with the replication method. Éndoxa, Madrid, n. 19, p. 315-40, 2005.

LEDERMAN, N. G., ABD-EL-KHALICK, F. Avoiding de-Natured Science: Activities That Promote Understandings of the Nature of Science. In: MCCOMAS, W. F (Ed). The nature of science in science education: Rationales and strategies. Dordrecht, The Netherlands: Kluwer Academic Publishers, 1998, p. 83-126.

METZ, D.; STINNER, A. A role for historical experiments: capturing the spirit of the itinerant lecturers of the 18th century. Science \& Education, v. 16, n. 6, p. 613-624, 2007.

MOREIRA, M. A. Mapas conceituais e diagramas V. Porto Alegre, 2006.

NETO, J. S.; CAVALCANTI, C. J. H.; OSTERMANN, F. Estratégias discursivas adotadas por professores em formação na compreensão do fenômeno da complementaridade em atividades didáticas mediadas pelo interferômetro virtual de Mach-Zehnder. Revista Brasileira de Pesquisa em Educação em Ciências, São Paulo, v. 15, n. 2, p. 293-320, mai/ago. 2015.

PEREIRA. P. A.; OSTERMANN, F. Sobre o ensino de física moderna e contemporânea: uma revisão da produção acadêmica recente. Investigação em Ensino de Ciências, Porto Alegre, v. 14, n. 3, p. 393-420, dez. 2009.

VALADARES, J. Organizadores gráficos facilitadores da Aprendizagem Significativa: Diagramas em Vê e Mapas conceituais. Coleção Educação e Desenvolvimento. Lisboa: UIED, 2014.

ZABAlA, A. A Prática educativa: como ensinar. Tradução: Ernani F. da F. Rosa. Porto Alegre: Artmed, 1998. 224 p.

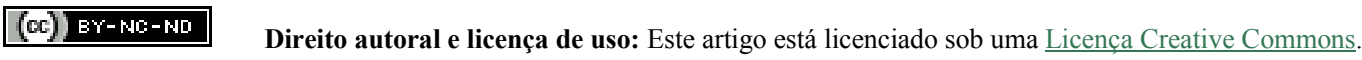

